Editorial

\title{
Naloxone as a Harm Reduction Initiative: Misinterpretations of Research
}

\author{
Richard R. Massatti \\ Ohio Department of Mental Health and Addiction Services, United States
}

In the American Medical Journal, Annahita Beheshti and colleagues review the literature on naloxone use for opioid overdose in West Virginia (Beheshti et al., 2015). The authors cite several of my publications in support of their views on naloxone (Massatti, 2013; Massatti et al., 2014), but many of these citations misinterpret my work by using it to present a counterargument against the drug. Specifically, the authors make false assumptions when they imply the availability of an antidote might lead to increased opioid use. Beheshti et al. (2015) say, "the availability of an antidote may encourage drug use by providing a sense of security in users" (in page 11, para. 4, lines 1-8); however, there is no citation except for my work. While it is true Massatti (2013) suggests there is anecdotal evidence that persons abusing opioids travel to areas more likely to have naloxone (e.g., hospital parking lots and communities where EMTs are more likely to carry naloxone; in page 18 , para. 2 , lines $1-8$; in page 18 para. 3 , lines $1-8$ ), there is no evidence that increased access leads to increased use. Simply put, location may change in some cases, but incidence does not. Beheshti et al. (2015) also generally overstate the link between naloxone availability and opioid use when they say, "there is little evidence supporting the effectiveness of naloxone in deterring illegal use of opioids" (in page 10, para. 1, lines 4-6). The purpose of making naloxone more accessible is to reduce the number of unintentional overdose deaths, not to deter illicit use of opioids. As is oft said when discussing naloxone, "Dying is not a good way to recover."

Beheshti et al. (2015) continue their line of reasoning and erroneously suggest that increased availability of naloxone raises the likelihood of overdose episodes. Beheshti et al. (2015) correctly cite my work that EMTs report persons fearing prosecution have abandoned overdose victims, but then they follow up that point with a speculation about use of 911 services. Beheshti et al. (2015) explain, "If naloxone were to be available over the counter, sufficient use of 911 emergency could diminish and the incidence of overdose will likely continue to increase" (in page 12, para. 2, lines 24-27). My work cannot be used to draw those conclusions because it does not discuss a relationship between Over-
The-Counter (OTC) use of naloxone and 911 emergency services. Moreover, the literature does not support the assertion that increased availability of naloxone leads to more frequent overdose episodes.

Furthermore, the authors mistakenly suggest that legal changes may lead to increased use. Beheshti et al. (2015) state,"Additionally, the rate of naloxone use has increased for every age group from 2003-2012 in Ohio suggesting that relaxed laws governing the use of naloxone may lead to increased use " (in page 11, para. 2 , lines 8-11). The authors are confusing cause and effect because they are not placing events in the correct temporal order. Ohio's scope of practice statements and formal house bills expanding the use of naloxone were not enacted until late 2013 (ODPS, 2014; OLSC, 2014); therefore, it was impossible that "relaxed laws" had anything to do with the relationship between increased opioid use and increased naloxone administration from 2003 to 2012 .

In another example, Beheshti et al. (2015) claim that my work advocates for OTC use because visiting with a physician hinders the potential success of naloxone (in page 11, para. 3, lines 10-13). Once again, Massatti (2013) does not reference OTC prescription of naloxone, nor does it ever indicate that visiting with a physician hinders the potential success of the drug. Massatti et al. (2014) merely discuss Ohio House Bill 170 that allows physicians and other health care professionals to furnish or prescribe naloxone to friends and family members of those at-risk of opioid-related overdose (in page 7, para. 3, lines 3-6). Recommendations are also made for naloxone's prescription to at-risk groups (e.g., persons leaving or in outpatient substance abuse treatment for opioid abuse or dependence) and co-prescription of naloxone for certain individuals (e.g., individuals receiving $\geq 80$ morphine equivalent doses; in page 8 , para. 2, lines 1-9).

The misrepresentation of my work by Beheshti et al. (2015) is dangerous because naloxone is used to save lives. It is difficult to imagine what would have happened if naloxone had not been used over 154,000 times by emergency medical technicians in 2014 (NEMSIS, 2015). No empirically based argument currently exists to limit access to naloxone and my 
body of work supports access to this life-saving drug to all professionals and laypersons who could save the life of an overdose victim. Naloxone is desperately needed now more than ever to save the lives of persons impacted by opioid addiction and any conflation of the facts with fiction may create a narrative that could cost people their lives.

\section{References}

Beheshti, A., L. Lucas, T. Dunz, M. Haydash and H. Chiodi et al., 2015. An evaluation of Naloxone use for opioid overdoses in West Virginia: A literature review. Am. Med. J., 6: 9-12.

DOI: 10.3844 /amjsp.2015.9.13

Massatti, R., 2013. Naloxone (Narcan $\left.{ }^{\circledR}\right)$ Administration in Ohio, 2003-2012. Ohio Department of Mental Health and Addiction Services, Columbus, $\mathrm{OH}$.
Massatti, R., C. Beeghly, O. Hall, M. Kariisa and L. Potts, 2014. Increasing heroin overdoses in Ohio: Understanding the issue. Ohio Department of Mental Health and Addiction Services, Columbus, $\mathrm{OH}$.

NEMSIS, 2015. Create a report (NEMSIS cube). National EMS Information System.

ODPS, 2014. Local Naloxone education assistance training. Ohio Department of Public Safety.

OLSC, 2014. Sub. H.B. 170. 